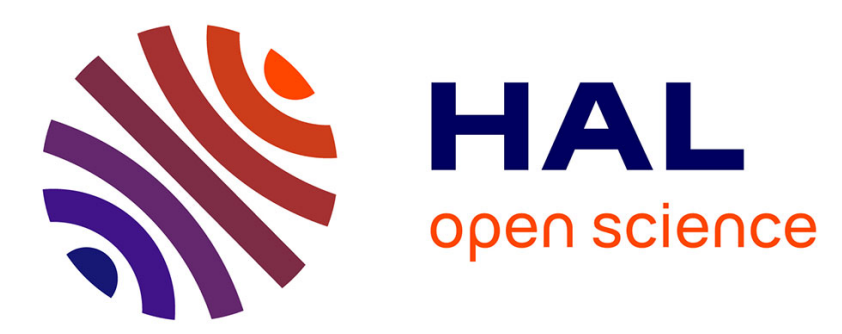

\title{
Phase Behavior of a Pd-Cu Bimetallic Catalyst During Temperature-Programmed Reduction
}

\author{
M. Fernández-García, G. Haller
}

\section{To cite this version:}

M. Fernández-García, G. Haller. Phase Behavior of a Pd-Cu Bimetallic Catalyst During TemperatureProgrammed Reduction. Journal de Physique IV Proceedings, 1997, 7 (C2), pp.C2-895-C2-896. 10.1051/jp4:1997269 . jpa-00255352

\section{HAL Id: jpa-00255352 https://hal.science/jpa-00255352}

Submitted on 1 Jan 1997

HAL is a multi-disciplinary open access archive for the deposit and dissemination of scientific research documents, whether they are published or not. The documents may come from teaching and research institutions in France or abroad, or from public or private research centers.
L'archive ouverte pluridisciplinaire HAL, est destinée au dépôt et à la diffusion de documents scientifiques de niveau recherche, publiés ou non, émanant des établissements d'enseignement et de recherche français ou étrangers, des laboratoires publics ou privés. 


\title{
Phase Behavior of a Pd-Cu Bimetallic Catalyst During Temperature- Programmed Reduction
}

\author{
M. Fernández-García and G.L. Haller* \\ Instituto de Catálisis y Petroleoquímica, CSIC, Campus Cantoblanco, 28049 Madrid, Spain \\ * Chemical Engineering Department, Yale University, 9 Hillhouse Avenue, New Haven, CT06520-8286, \\ U.S.A.
}

\begin{abstract}
The phase behavior of a $1 \% \mathrm{Pd}-0.5 \% \mathrm{Cu}$ bimetallic catalyst during reduction has been followed by X-ray absorption near-edge structure (XANES). The analysis of the XANES spectra by Factor Analysis was used to determine that after calcination the active components are hosted in three different phases: a $\mathrm{Cu}-\mathrm{Pd}$ mixed oxide, $\mathrm{PdO}$ and $\mathrm{Cu}^{\mathrm{n}+}$ ions exchanged into $\mathrm{L}-\mathrm{zeolite}$ positions. At the Pd K-edge, an intermediate compound is detected in the reduction process. The reduction of the catalyst yields only one phase, a substitutionally disordered $\mathrm{Pd}_{50} \mathrm{Cu}_{50}$ alloy.
\end{abstract}

\section{INTRODUCTION}

In order to control the physical, e.g. dispersion, and chemical, e.g. reactivity, properties of a metallic catalyst it is necessary to understand the genesis of the active phase during the activation (reduction) treatment. In a bimetallic system this task is complicated by the fact that several compounds, mono or bimetallic, may coexist in a temperature range during the treatment. We have attempted to address this problem by applying a statistical method to a set of XANES spectra obtained during a termperature-programmed reduction (TPR) experiment [1]. This mathematical method makes possible the estimation of the number of metal-containing species and the study of their evolution throughout the treatment.

\section{EXPERIMENTAL AND COMPUTATIONAL DETAILS}

A bimetallic catalyst containing $1 \% \mathrm{Pd}$ and $0.5 \%$ of $\mathrm{Cu}$ (approx. 1:1 Pd:Cu atomic ratio) was prepared by coimpregnating $\mathrm{KL}$-zeolite with nitrate precursors at $\mathrm{pH} 8$ and calcined in pure $\mathrm{O}_{2}$ at 573K. XANES spectra at the Cu K-edge were recorded during reduction ( $5 \%$ vol, $\mathrm{H}_{2} / \mathrm{He}, 5 \mathrm{~K} / \mathrm{min}$ ) at the National Synchrotron Light Source (Brookhaven, NY, USA) using a double-crystal $\mathrm{Si}(111)$ monocromatror with a estimated resolution of $0.7 \mathrm{eV}$. Self-supporting wafers with an absorbance of 2 were measured in the transmission mode using nitrogen filled ionization chambers. The Pd K-edge was studied using the F-2 wiggler line at Cornel1 High Energy Synchrotron Source (Ithaca, NY, USA) with a double crystal Si(220) at an estimated resolution of $1.4 \mathrm{eV}$. Experiments were conducted with self-supporting wafers with an absorbance of 0.37 (c.a. $350 \mathrm{mg}$, diffusion or temperature related problems prevent the use of significantly larger amounts of sample) in the transmission mode using argon flowing ionization chambers. On both edges, the energy scale was calibrated simultaneously to the measurements by using a foil placed in a third ionization chamber.

Factor Analysis (FA) was used to extract chemical information from the sets of XANES spectra obtained on the Pd and $\mathrm{Cu}$ K-edges. Principal Component Factor Analysis is applicable to a variable, the absorbance in a set of spectra, that can be modeled as a linear sum of uncorrelated components, called factors [2]. The target of FA is to decompose a data matrix D, constituted of c spectra, into a row matrix, $R$, which contains basic spectra components (factors), and a column matrix, $C$, which elements corresponds to the concentration of the components in each original spectrum of $\mathrm{D}$. Through the statistical analysis of the (vectorial) magnitude of the basic spectra components, called eigenvalues (because of the mathematical procedure used to obtain them), it is decided if a factor is dominated by signal or noise; this is based in an $F$ test of the variance associated with a $k$ th component (factor) and the summed variance associated with noise components $(k+1, \ldots, c)$. A component is accepted as signal if the percentage of significance level (\%SL) corresponding to the probability of the $\mathrm{F}$ ratio of both variances being higher than the calculated value is lower than a test level that previous work recommends to be set at $5 \%[1,3]$. To help in deciding the number of principal components, i.e. components associated with signal, the ratio between two consecutive reduced eigenvalues was also used. This ratio (REVR ratio) approaches one when two error eigenvalues are compared but it is significantly greater if one eigenvalue is responsible for signal [2]. After determination of the number of principal components, a rotation of the $\mathrm{R}$ and $\mathrm{C}$ matrixes is performed to obtain the physically meaningful solution. The transformation matrix required is calculated by a self-consistent iterative process based on Iterative Transformation Factor Analysis (ITFA) [4]. To determine the starting point in the iterative process, the $\mathrm{C}$ matrix is orthogonally transformed by a 
varimax rotation to approach concentration profiles showing maxima. The ITFA method yields XANES spectra corresponding to pure $\mathrm{Pd}$ or $\mathrm{Cu}$ species and their concentration profiles along the reaction coordinate, the temperature during the TPR experiment $[1]$.

\section{RESULTS AND DISCUSSION}

The \%SL and REVR values reported on Table 1 indicate the existence of three principal components in each absorption edge. In the Cu K-edge (solid symbols in Fig. 1) two of these species are present after calcination (oxidized species) and only one is observed at higher temperatures. The species corresponding to solid triangles does not present a characteristic temperature of reduction, a behavior that indicates a $\mathrm{Pd}-\mathrm{Cu}$ mixed oxide. The other $\mathrm{Cu}$-containing oxidized species has a XANES spectrum shape (Fig. 2) ascribable to $\mathrm{Cu}^{\mathrm{n}+}$ cations exchanged into L-zeolite positions. The Pd K-edge only shows the presence of one oxidized species that may be then assigned to the Pd-Cu mixed oxide already mentioned. However, because $P d$ ions in PdO and Pd-Cu mixed oxides have the sarne local symmetry and distance to nearest neighbor $\mathrm{O}^{2-}$ ions [1], these chemical compounds are hardly distinguishable by XANES and, consequently, both are likely contributing to the mentioned concentration profile (open triangles). This fact explains the different behavior observed between the open and solid triangle concentration profiles at low temperatures. At the Pd K-edge, an intermediate compound of the reduction process is detected (open circles). This compound has not been yet identified but its edge position suggests a partially oxidized species. At temperatures higher than $623 \mathrm{~K}$ both edges show the presence of one species (for the sake of clarity only that corresponding to the $\mathrm{Cu}$ K-edge has been included in Fig. 1). Therefore, complete alloying of both metals is reached on reduction. An analysis of the continuum resonance positions of the bimetallic compound XANES spectrum on both edges shows unequivocally that this zero valent species is a substitutionally disordered $\mathrm{Pd}_{50} \mathrm{Cu}_{50}$ alloy [5].

Table 1. Principal component analysis for $1 \% \mathrm{Pd}-0.5 \% \mathrm{Cu} / \mathrm{Kl}$-zeolite catalyst.

\begin{tabular}{ccccccc} 
Factor & Cu K-edge eigenvalue & \%SL & REVR & Pd K-edge eigenvalue & \%SL & REVR \\
\hline \hline 1 & 595.382 & 0.00 & 552.76 & 607.563 & 0.00 & 512.46 \\
2 & 1.00751 & 0.00 & 117.44 & 1.07252 & 0.01 & 8.942 \\
3 & 0.00800 & 0.77 & 4.27 & 0.10761 & 0.29 & 11.10 \\
4 & 0.00174 & 7.97 & 1.44 & 0.00869 & 22.79 & 1.50 \\
\hline
\end{tabular}

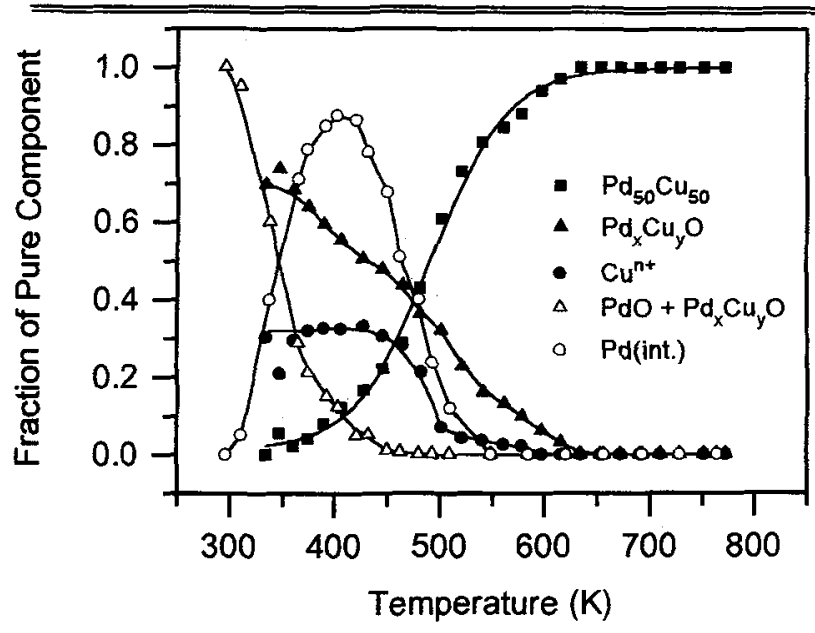

Figure 1: Concentration profiles along the reduction coordinate. Open symbols, Pd K-edge species; Solid symbols, Cu K-edge species.

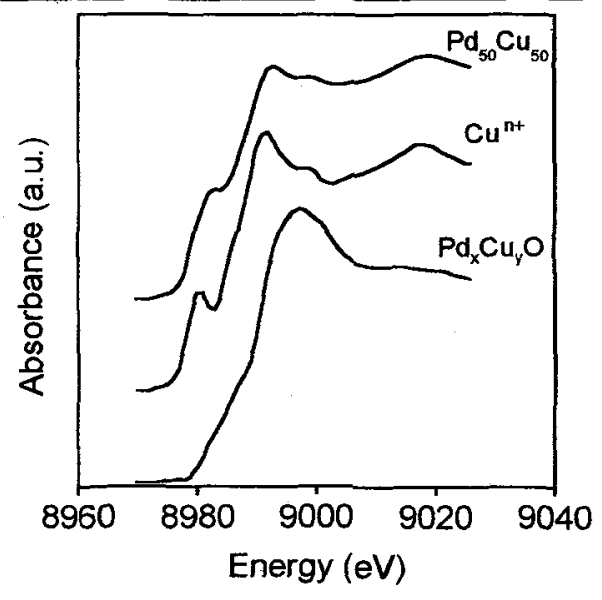

Fig. 2: Predicted Cu K-edge pure components.

\section{REFERENCES}

[1] Fernández-García M., Márquez Alvarez C., Haller G.L., J. Phys. Chem. 99 (1995) 12565.

[2] Malinowski E.R., Factor Analysis in Chemistry (Wiley, New York, 1991).

[3] Fernández-García M., Márquez Alvarez C., Rodríguez-Ramos I., Guerrero-Ruiz A., Haller G.L., J. Phys. Chem. 99 (1995) 16380.

[4] Gemperline P.J., Chem. Inf. Comput. Sci. 24 (1984) 206.

[5] Fernández-García M., Anderson J.A., Haller G.L., unpublished results. 